\title{
Stress Fields in Central Portions of the Pacific Plate: Delineated in Time by Linear Volcanic Chains
}

\author{
EVERETT D. JACKSON
}

\author{
U.S. Geological Survey, Menlo Park, California 94025
}

\author{
Herbert R. Shaw
}

Department of Geology and Geophysics, University of Califormia. Berkeley, Calijornia 94720

\begin{abstract}
Many linear island chains in the Pacific appear to consist of individual volcanic shields that lie on relatively short, curved loci sometimes of sigmoidal form. These loci, in turn, lie at an angle to the directions of propagation of the chains. Those chains that now trend just south of east (the Pratt-Welker, Hawaiian, Tuamotu, and Austral chains) consist of en echelon sets of loci with right lateral (clockwise) sense of stepwise overlap, whereas the supposed older extensions of these chains that lie nearly northsouth (the Emperor and Ellice-Gilbert-Marshall chains) consist of sets of loci with left lateral (counterclockwise) sense of stepwise overlap. Rift zones of isolated volcanoes in the chains, that is, those volcanoes whose local stress fields were not influenced by the buttressing effects of near-neighbor volcanoes at the time of their formation, show the same orientation as the loci. First-motion studies of earthquakes in the Pacific lithosphere to date are few in number and give a variety of solutions with inferred directions of maximum principal compression $(P)$ nearly horizontal and trending in both northeasterly-southwesterly and northwesterly-southeasterly directions. However, the number of such solutions is small, in some cases related to edifice effects, and interpretations relating compression and dilatation to principal stress directions in magmatic source regions are open to question. We consider it likely that the dominant orientation patterns have been due to dynamic effects related to the overall kinematic patterns of Pacific plate motions. Although a large number of different factors can influence the inherent and transmitted stresses in the lithosphere, and thereby influence the locally dominant stress field, we conclude that the effective stress orientations in the very recent past and for about the last $40-50$ m.y. can be considered to have been caused by dynamic forces reflected in a right lateral rotational couple acting within the plane of the Pacific plate. These forces have induced maximum $\left(S_{1}\right)$ principal compressional stress directions that have had surface traces trending about northwest-southeast, relating to minimum $\left(S_{3}\right)$ principal stress directions that have trended northeast-southwest. Prior to $40-50 \mathrm{~m} . \mathrm{y}$. ago the dominant stress orientations in the plate were caused by a tendency for left lateral stress rotations, which induced maximum $\left(\boldsymbol{S}_{\mathbf{i}}\right)$ principal compressional stress directions with surface traces that trended just west of north and minimum $\left(S_{s}\right)$ principal stress directions that trended just north of east. These data and interpretations are independent of whether or not a change in direction of motion of the Pacific lithospheric plate took place roughly at the time represented by the bends in the island chains and are also independent of arguments as to whether melting anomalies of the Pacific are rigidly fixed or whether they are better explained in terms of thermal plumes or gravitational anchors. We conclude that the trends and age correlations of volcanic loci in the Pacific accurately track and identify the evolution of states of stress in the Pacific lithosphere with time. As more age data for linear island edifices become available, it should be possible to construct a Pacific-wide chronology of volcanism independent of but similar to that developed from magnetic reversals. Further, it appears that changes in stress directions in the plate have been episodic and that they may correlate with episodic magma generation not only in the central part of the Pacific plate but also around its margins.
\end{abstract}

\section{INTRODUCTION}

Dana $[1849$, p. 12] clearly noted the linear character of certain groups of islands in the Pacific Ocean. He noted 'The epithet scattered, as applied to the islands of the ocean, conveys a very incorrect idea of their positions.' In 1876 he clearly distinguished between what are now called island arcs (Dana's Australasian chain) and what are now called linear island chains (Dana's Hawaiian and Polynesian chains). He further noted that the latter chains were broken into short segments that succeeded and overlapped one another along the course of the chains. Dana's [1876, p. 32] Figure 27 is reproduced here as Figure 1. In Dana's opinion these aligned segments were in some way related to a worldwide fracture system. As bathymetric data became available, Dana [1897], Powers [1917], Williams [1933], Chubb [1934], and Betz and Hess [1942] examined various aspects of the relation of linear island chains to fracture systems. In 1970, when the original

Copyright (C) 1975 by the American Geophysical Union. bathymetric maps of Chase et al. [1973] were published, Jackson et al. [1972] proposed that individual volcanoes in the Hawaiian-Emperor chain lay on short, curved en echelon loci that were subparallel with respect to one another. Their map of loci is modified here as Figures 2 and 3. Jackson et al. [1972] attributed these loci to be a result of extensional features in the oceanic crust and upper mantle. It now seems possible to extend the interpretation of volcanic loci both in the HawaiianEmperor chain and in similar chains in other parts of the Pacific plate.

In this paper we contend that the volcanoes of the Pacific that form en echelon loci are positioned by changes in the stress field in the Pacific lithosphere with time and that the loci have accurately tracked directions perpendicular to the directions of the least principal stress in the Pacific plate over the last 70-100 m.y. These changes in the stress field have been oscillatory, even though they may not have been strictly periodic, and can be considered to have been the effects of rotations of resultant stresses acting within the plane of the Pacific plate 


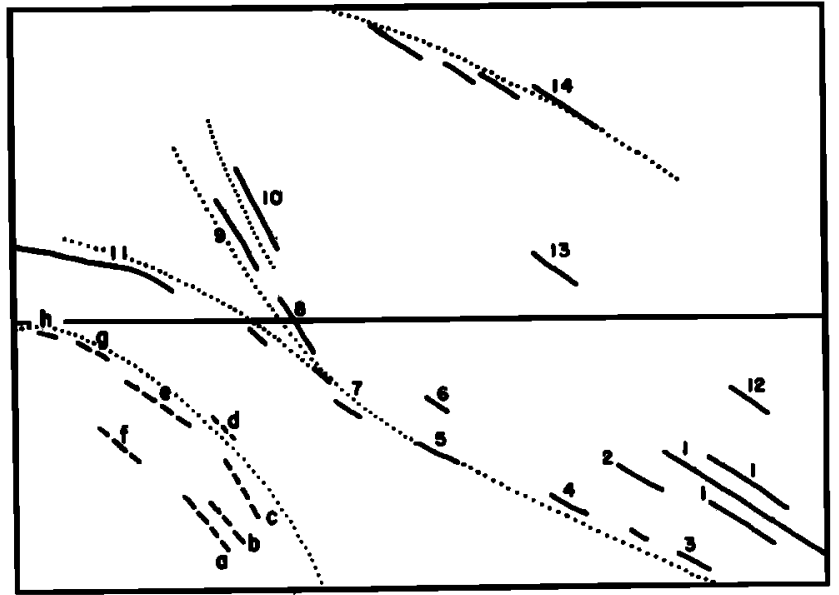

a

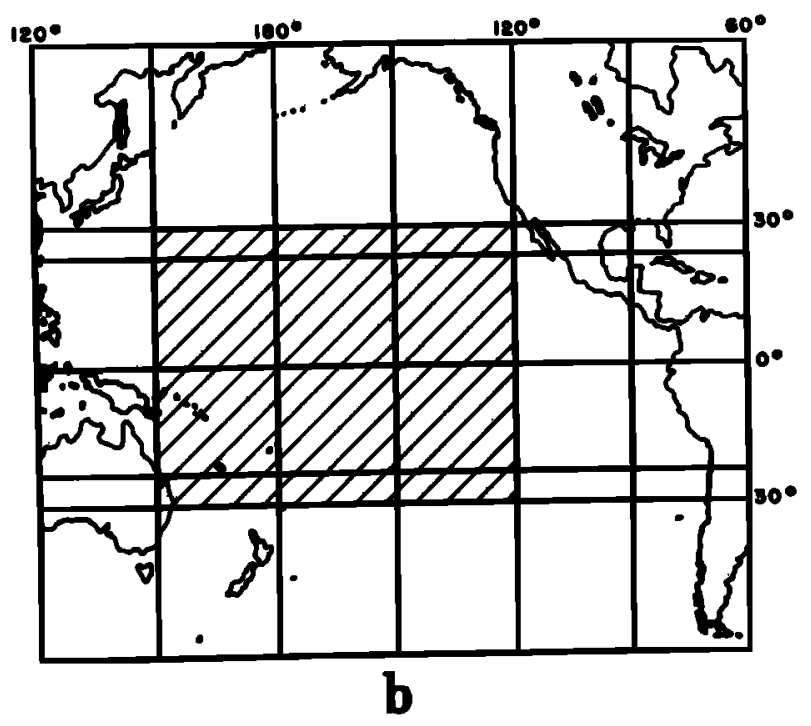

Fig. 1. (a) The Polynesian chain, 1-14: 1, Paumotu group; 2, Tahitian; 3, Rurutu group; 4, Hervey group; 5, Samoan, or Navigators; 6 , Vakaafo group; 7, Vaitupu group; 8, Gilbert's group; 9, Ralick; 10, Radack; 11, Carolines; 12, Marquesas; 13, Fanning group; 14, Hawaiian. Parts $a-h$ of the Australasian chain: $a$, New Caledonia; $b$, Loyalty group; $c$, New Hebrides; $d$, Santa Cruz group; $e$, Solomon Islands; $f$, Louisiade group; $g$, New Ireland; $h$, Admiraliy group (after Dana [1876, Figure 27b]; spellings are Dana's). (b) Index map of the Pacific showing location of Dana's map in inset.

that resulted from changing force balances at all plate boundaries. The variation of boundary forces does not imply that such forces do not sum to zero at all times. Whether or not there has been any rotational component of motion in the plane of the plate relative to translation about its kinematic pole is information that cannot be established at this time and is not necessary in order to produce the deduced rotations of stress orientations.

\section{En Echelon Character of Linear Island Chains}

Jackson et al. [1972, Figure 1] deduced the en echelon pattern of loci in the Hawaiian chain to be stepped to the right (clockwise) with respect to the direction of elongation of the chain as far as the Hawaiian-Emperor bend but stepped to the left (counterclockwise) in the Emperor chain itself. These loci were determined by connecting the centers of volcanic shields in such a way that the maximum number could be fitted to a single locus. The detailed location of former centers of volcanism and detailed criteria for the delineation of
Hawaiian-Emperor loci are given in the work by Bargar and Jackson [1974]. The best estimate of the age of volcanic rocks at the bend at this time is about $42-44 \mathrm{~m} . \mathrm{y}$. [Clague and Dalrymple, 1973; Dalrymple et al., 1974; Clague et al., 1975].

Morgan [1972a, b] suggested that the Austral-GilbertMarshall and Tuamotu-Line islands and seamounts form linear features similar to and parallel with the EmperorHawaiian chain. This contention has been challenged in detail by Clague and Jarrard [1973a] and Molnar and Atwater [1973], and indeed the bathymetry, petrology, and geochronology of these chains are not well-understood. Morgan [1972a] further considered a seamount chain that extends from the Gulf of Alaska toward Cobb seamount to be of the Hawaiian type. The most obvious segment of this linear feature is the PrattWelker chain of Turner et al. [1973], also called the KodiakBowie chain by Silver et al. [1974].

Age data for the Austral-Cook islands fall in the time span from 0 to 24 m.y. [Krummenacher and Noetzlin, 1966; Clague and Jarrard, 1973b; Dalrymple et al., 1975], and therefore these islands were formed during the same time span as the southeastern part of the Hawaiian chain, although the progression of measured ages appears complex. Scripps bathymetry [Mammerickx et al., 1973] is now available for this part of the Pacific, and the bathymetric data suggest that shield-shaped structures lie on curved loci, which appear to be stepped to the right (clockwise), as in the Hawaiian chain (Figure 4). It should be emphasized that due to extensive coralline cover the former centers of volcanism and the morphologic criteria required to construct accurate loci are somewhat obscured in this area.

Chase et al.'s [1973] revised bathymetry is available for the Ellice-Gilbert-Marshall chains, which have minimum ages between 37.5 and 100 m.y. [Clague and Jarrard, 1973b]. In view of the poor quality of the age information we can say only that it appears likely that these chains formed within about the same time span as the Emperor chain, in accord with Morgan's $[1972 a, b]$ suggestion. Short segments of Ellice-Gilbert-Marshall loci appear to be stepped to the left (counterclockwise) (Figure 5), although, again, coralline caps reduce the accuracy of loci determination.

Bathymetric data for the Line Islands are fairly good, but the chain is surrounded by thick turbidites and is complicated by structures such as the line cross of Clague and Jarrard [1973b]. We have been unable to construct segments of loci along the Line Islands-seamount chain, and recent deep-sea drilling results [Schlanger et al., 1974] suggest that great linear segments of the Line Islands formed coevally and, further, that they are unrelated to the Tuamotu chain in the manner proposed by Morgan [1972a, b]. Bathymetric data in the Tuamotu chain itself are as of this writing of very poor quality, and it seems premature to construct loci at this time. However, Apollo photography of the area (Figure 6) suggests that the chain is stepped to the right. Age data for the Tuamotu chain are scanty, but existing data [Clague and Jarrard, 1973b; Schlanger et al., 1974] suggest that it formed during roughly the same interval as the Hawaiian chain. We share Dana's [1876] view that the Tuamotu chain is stepped to the right (clockwise).

Turner et al. [1973, 1974] have recently determined the ages of four seamounts of the Pratt-Welker chain; they yield ages between 22.6 (Kodiak seamount) and 2.67 m.y. (Hodgkins seamount). Presumably, Kodiak seamount is the oldest edifice in the chain, and the entire group of islands was therefore formed during a part of the same time interval as the Hawaiian 
chain. The seamounts of the Pratt-Welker chain appear to lie on curved loci stepped to the right (clockwise) (Figure 7). Criteria for loci determination in this chain are obscured by sedimentary cover, but loci in this figure are plotted on a basement map constructed by Silver et al. [1974].

In summary, we have reexamined, in the light of presently available bathymetry, Dana's [1849, 1876] contention that linear island chains in the Pacific are aligned on short overlapping segments, and in general we concur with his observations. We further note that these segments, or loci of volcanoes, are stepped to the left on most linear chains that trend slightly west of north and have ages, to the best of our present knowledge, of greater than 40-50 m.y. On the other hand, those Pacific chains that trend generally northwest and that appear to be younger than 40-50 m.y. have loci that are stepped to the right. These observations are independent of arguments as to whether northerly or northwesterly chains in the Pacific have common rotation poles [Morgan, 1972a, $b$; Clague and Jarrard, 1973a; Molnar and Atwater, 1973; Silver et al., 1974] or as to whether a change of translation of the plate took place at the bends [Morgan, 1972a, b; Herron, 1972]. They are also independent of discussions as to whether the rate or direction of propagation of the chains is constant or episodic [Morgan. 1972a, b; Jackson et al., 1972; Shaw, 1973; Shaw and Jackson, 1973].

\section{Loci That Delineate Stress Fields}

Fiske and Jackson [1972] recently published a compilation of the rift orientations of Hawaiian shields, combined with an experimental study that consisted of injecting fluids into gelatin models simulating different types of volcanic edifices. These authors concluded that either natural or experimental liquids injected into a viscoelastic medium inevitably mapped the in situ maximum $\left(S_{1}\right)$ and minimum $\left(S_{3}\right)$ principal stress directions of the medium. In the case of natural Hawaiian dike systems, rift directions were strongly influenced by stresses induced by nearby volcanic edifices, but in volcanoes without close neighbor edifices, northwesterly trends prevailed. In the experimental models, dikelike injected fluids faithfully followed maximum principal stress directions (i.e., along surfaces normal to the $S_{3}$ direction) through loaf-shaped, curved, and domed models. It is our contention that the loci are, in a similar way, evidence of volcanic fluids mapping stress fields in the Pacific plate.

Jackson et al. [1972] raised the puzzling problem of why loci were composed of strings of individual shield volcanoes rather than being manifested as single continuous volcanic ridges. We now propose that the formation of individual shields along loci is a result of the same process that causes the familiar "curtain of fire' eruptions in Hawaii. In reality these eruptions represent a series of closely spaced point source vents that coalesce into a centrally located single vent as eruptions progress in time [Stearns. 1966; Macdonald and Abbot, 1970; Richter et al., 1970]. We would now explain the curtain of fire behavior as representing initial eruption from many point sources along a fissure. The sources at the ends of such a fissure tend to have slower flow rates owing to greater viscous drag effects along the converging walls of the fissure. Also,

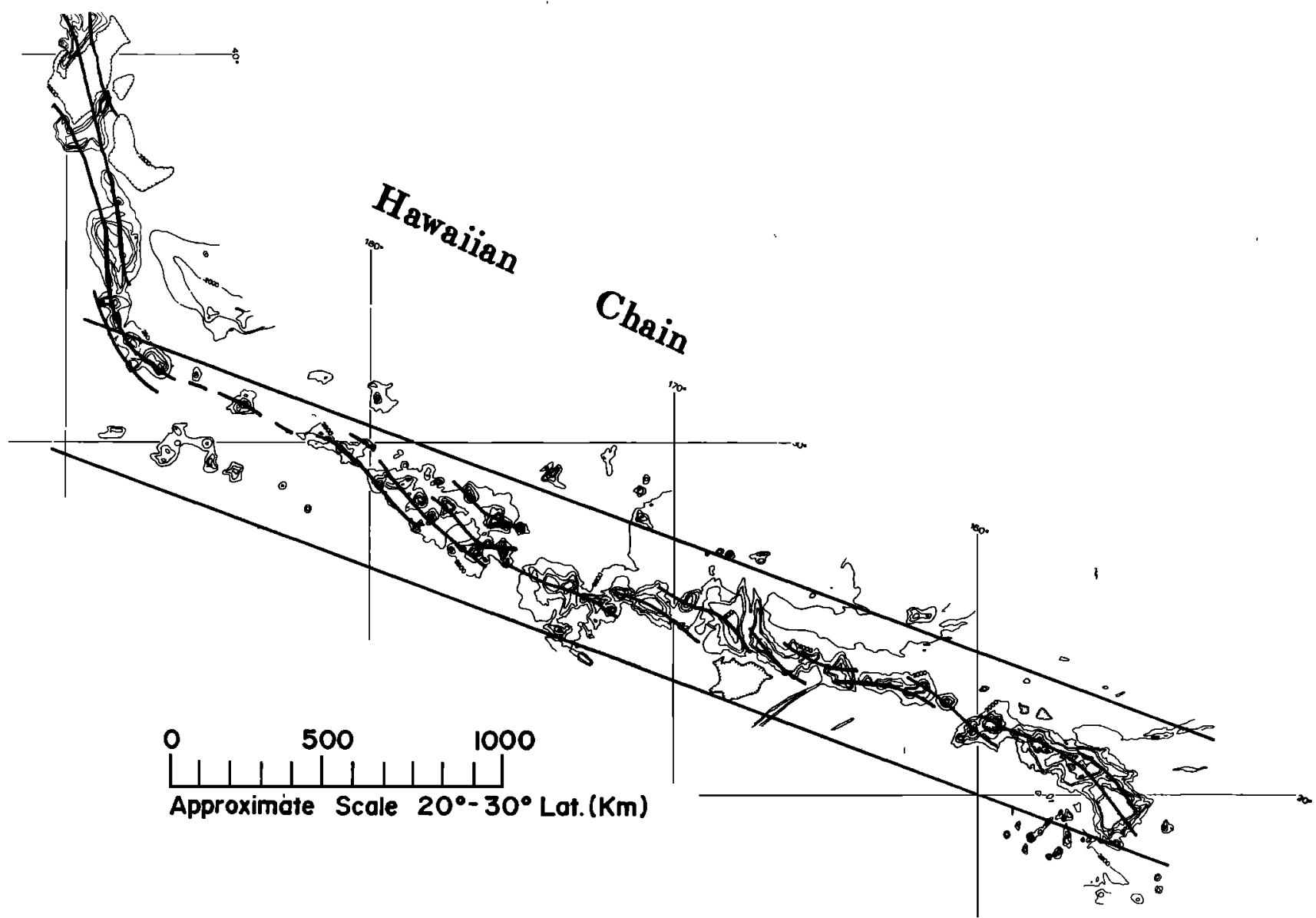

Fig. 2. Bathymetry and loci of individual shield volcanoes along the Hawaiian chain. Straight lines mark the outer boundaries of outer shields [after Bargar and Jackson, 1974]. Bathymetry is simplified from revised editions of Chase et al. [1973]. 


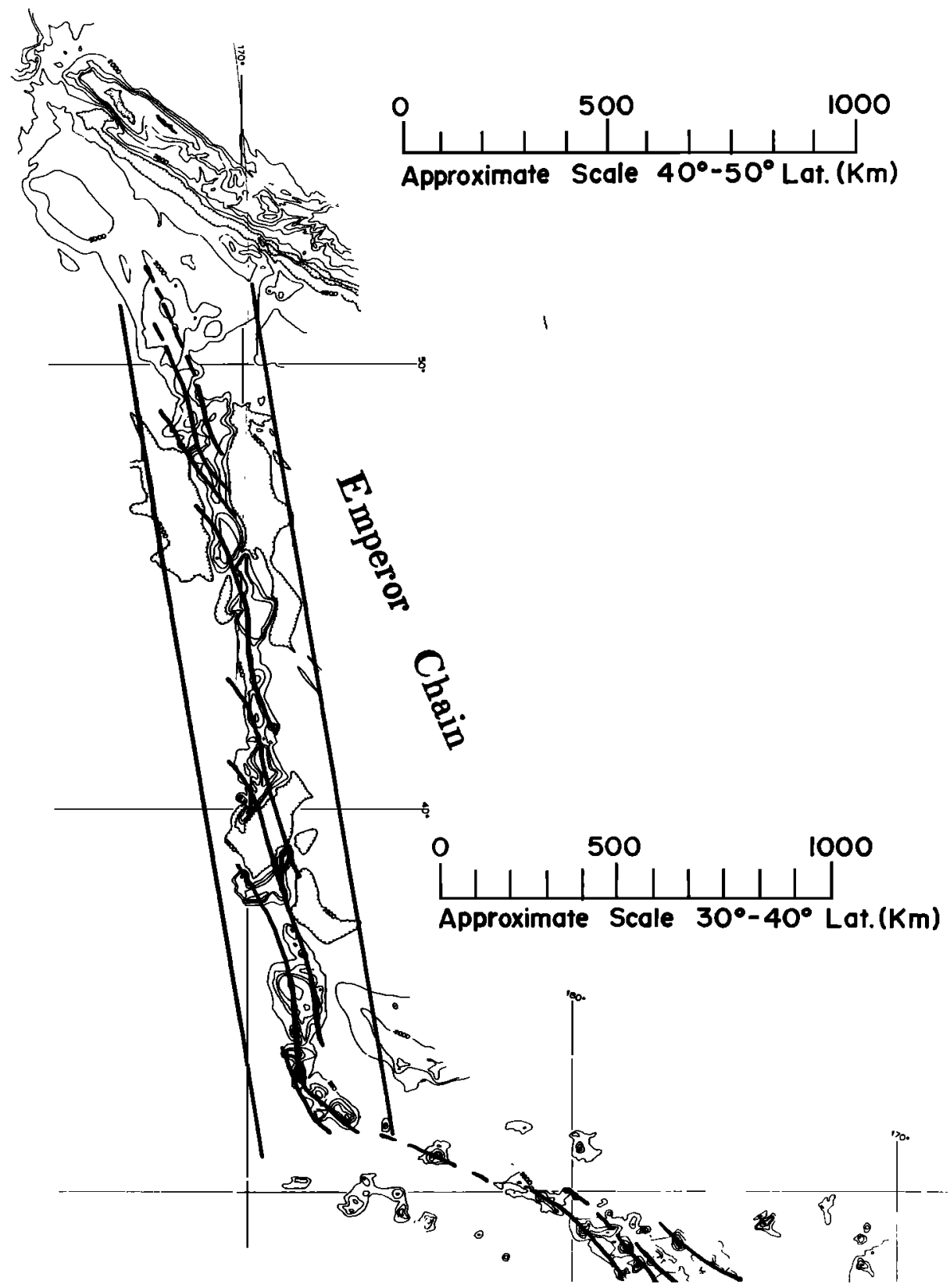

Fig. 3. Bathymetry and loci of individual shield volcanoes along the Emperor chain. Straight lines mark the outer boundaries of outer shields [after Bargar and Jackson. 1974]. Bathymetry is simplified from revised editions of Chase et al. [1973].

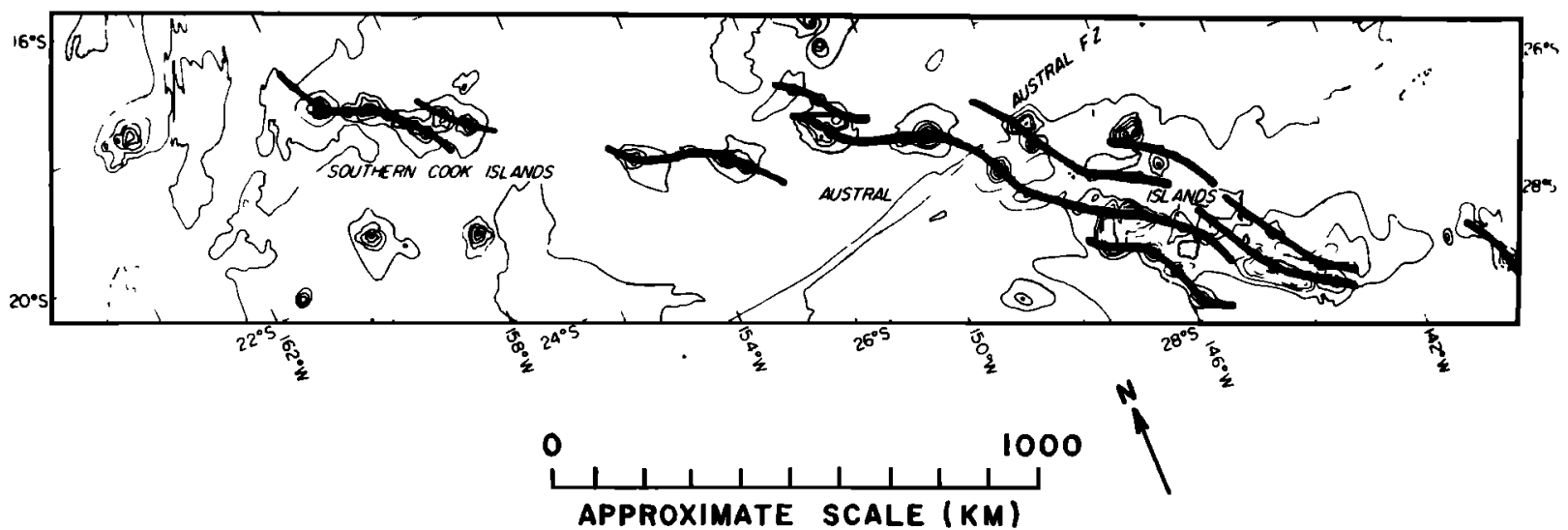

Fig. 4. Bathymetry and loci of individual shield volcanoes along the Austral chain. Straight lines mark the outer boundaries of outer shields. Bathymetry is from Dalrymple et al. [1975]. 
cooling is faster near their termination, and as a result, most of the flow tends to become channeled into central regions. In other words, in a slotlike conduit, any lateral variations of vertical flow rates of fluids with temperature sensitive viscosities tend to be enhanced where the flow is greater and reduced where flow is less. Planar flow of lava thus tends to be reduced to one or more pipelike channels. Given the same total flow rate, the cylindrical conduit is thermally the more efficient mode of transfer, larger distances of transport being permitted for the same volume rate of supply.

It seems likely to us that when a new edifice begins to form on the ocean floor, it would indeed begin initially with a series of fissure eruptions along a line marking the normal to the minimum principal stress axis (i.e., normal to $S_{\mathrm{a}}$ direction) in the lithosphere. This direction is also the direction of the trace of the maximum principal stress axis ( $S_{1}$ direction) on a map of the earth's surface in all cases except where the $S_{1}$ direction is vertical. These fissures, like the smaller-scale Hawaiian curtain of fire eruptions, would tend to become centralized for the same reasons as given above. Once channeled, individual shield-shaped volcanoes, rather than continuous volcanic ridges, would continue to grow and tend to lie on loci that trace the larger-scale stress systems. Furthermore, we interpret the curvature of the loci as mapping changes in the orientation of dominant stress fields with time.

\section{RifT ZoNe ORIENTATIONS}

Fiske and Jackson [1972] have described and interpreted the orientations of rift zones for the individual tholeiitic shield volcanoes in the southeastern part of the Hawaiian chain, where both rift orientations and age relations are well-known. All the shields and rift zones studied grew within the last $6 \mathrm{~m} . \mathrm{y}$. Fiske and Jackson mainly considered the relative importance of gravitationally induced stresses caused by the masses of nearby preexisting edifices and the local volcanic structure in determining the orientation of the rift systems of the shields. They examined the rift systems of both buttressed and isolated volcanoes (their Figures 16 and 17 are modified here in Figures 8 and 9). For comparison we have plotted the Hawaiian loci from Figure 2 on a similar rose diagram (Figure 10). It seems apparent that where local buttressing has not overshadowed the regional stress field, the rift zones follow the same pattern as the loci and, on the average, diverge about $20^{\circ}$ clockwise from the general attitude of the Hawaiian Archipelago.

\section{Direct Measurement of Present-Day Stress Orientations in the Pacific Plate}

A test of present-day stress states in the Pacific plate could, of course, be made by direct measurements of stress directions in the Pacific lithosphere. Direct in situ measurements, at least on land, probably would reflect the buttressed edifice stresses discussed by Fiske and Jackson [1972] but might reflect regional stresses if they are confined to isolated edifices. Studies of first motions of earthquakes that occur in the Pacific lithosphere either away from edifices or in depth ranges 20-60 $\mathrm{km}$ beneath edifices offer a potentially promising approach to determining regional present-day stress fields.

Stress orientations in the Pacific lithosphere derived from earthquake studies have, in fact, represented the principal source of information on present-day stress states in the plate. It would seem that a direct correlation should exist between the stress directions inferred from the volcanic loci above and the inferred stress directions derived from solutions of earthquake focal mechanisms. However, the stress pattern of

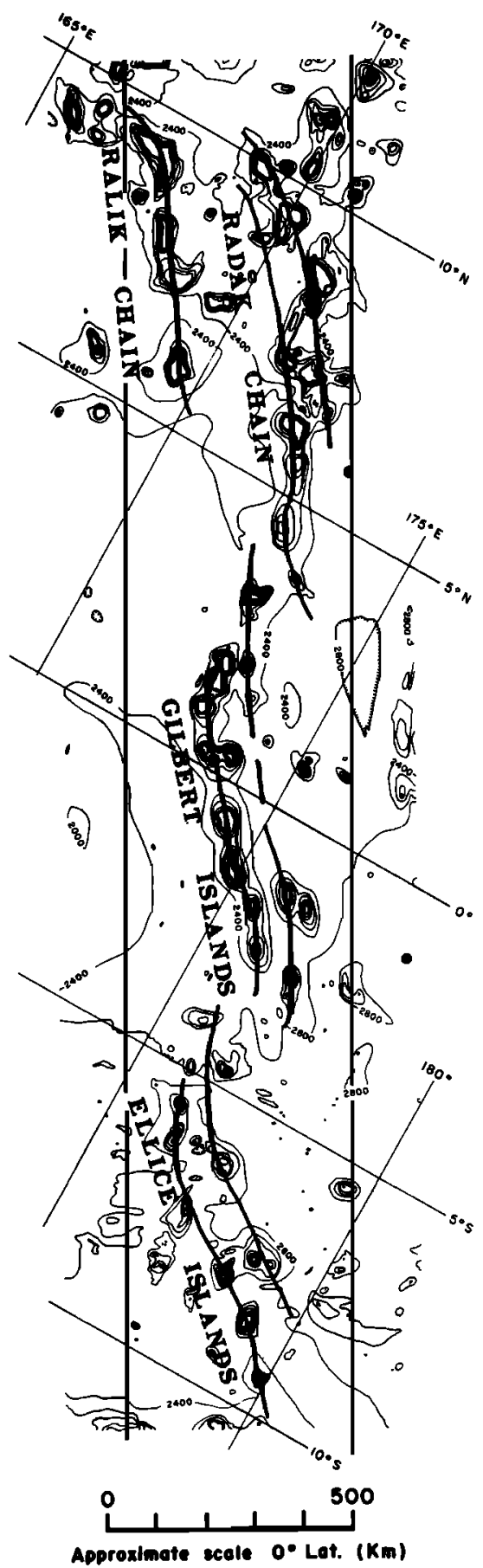

Fig. 5. Bathymetry and loci of individual shield volcanoes along the Marshall-Gilbert-Ellice chain. Straight lines mark the outer boundaries of outer shields. Bathymetry is simplified from revised editions of Chase et al. [1973] and Mammerickx et al. [1973].

Kilauea, the youngest volcanic edifice in the Pacific, could have been set 20,000-200,000 years ago, and the possibility exists that the dominant stress field could have changed since that time.

The following first-motion studies in the central Pacific, all based on the double-couple assumption, include those of which we are presently aware.

On June 27, 1962, a magnitude 6.1 earthquake occurred at an 8-km depth near the Kaoiki fault system between Kilauea and Mauna Loa [Koyanagi et al., 1966]. Fault plane solutions were consistent with strike slip movement on one of two planes 


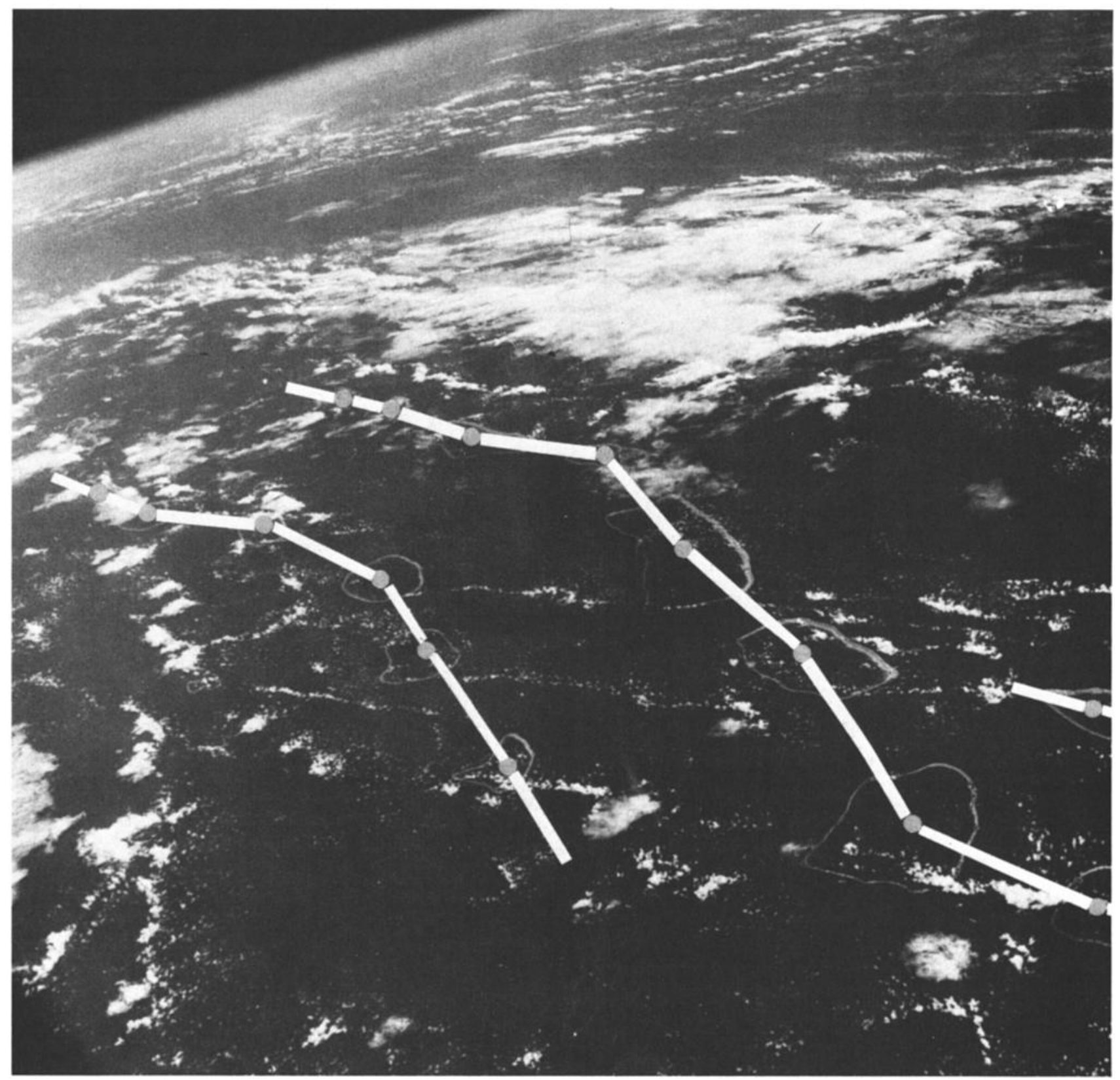

Fig. 6. Apollo 7 photograph of the atolls of the Tuamotu chain, looking southeast (NASA photograph AS7-4-1590). At least two curved right lateral loci can be observed and perhaps the end of a third at the extreme right edge of the photograph.

whose bisection in the dilatational quadrants at several stations (inferred $P$ ) was $N 75^{\circ} \mathrm{E}$. However, the earthquake was not only shallow by reason of its location within an edifice, but it was also near a rift system oriented in nearly the same direction as one of the planes dividing compressional from dilatational arrivals. It seems more likely therefore to have more local than regional significance.

On April 26, 1973, a magnitude 6.2 earthquake occurred at a 46-km depth about $25 \mathrm{~km} \mathrm{NNE}$ of Hilo, at the northern end of the island of Hawaii (P. L. Ward, personal communication, August 5, 1973) [Unger and Ward, 1974]. In this case, fault plane solutions were also consistent with strike slip motion but with an inferred $P$ direction at about $N 70^{\circ} \mathrm{E}$. The inferred $P$ directions of both the Kaoiki and the Hilo earthquakes are surprisingly similar, since they occurred at different positions and significantly different depths.
Koyanagi and Endo [1971] have shown that during 1969 and 1970 there was an almost continuous vertical distribution of earthquake hypocenters beneath Kilauea, ranging from depths of a few kilometers to depths of $45 \mathrm{~km}$. They showed an inverted funnel distribution that extends from the base of the crust (near $16 \mathrm{~km}$ ) to depths of $45 \mathrm{~km}$, still well within the lithosphere. Careful inspection of Koyanagi and Endo's [1971] Figure 5 suggests that the deepest earthquakes have distributions trending to the southeast, consistent with the source model of Shaw and Jackson [1973]. Shallower earthquake hypocenters are concentrated laterally along the rift zones. First-motion studies of a swarm of 1970 earthquakes on the east rift zone of Kilauea, all between near surface and $6 \mathrm{~km}$ deep, were essentially consistent with strike slip motion and inferred $\boldsymbol{P}$ directions parallel to the east rift zone (roughly $\mathrm{N} 50^{\circ} \mathrm{W}$ in this area) and to the Koae fault system (roughly 


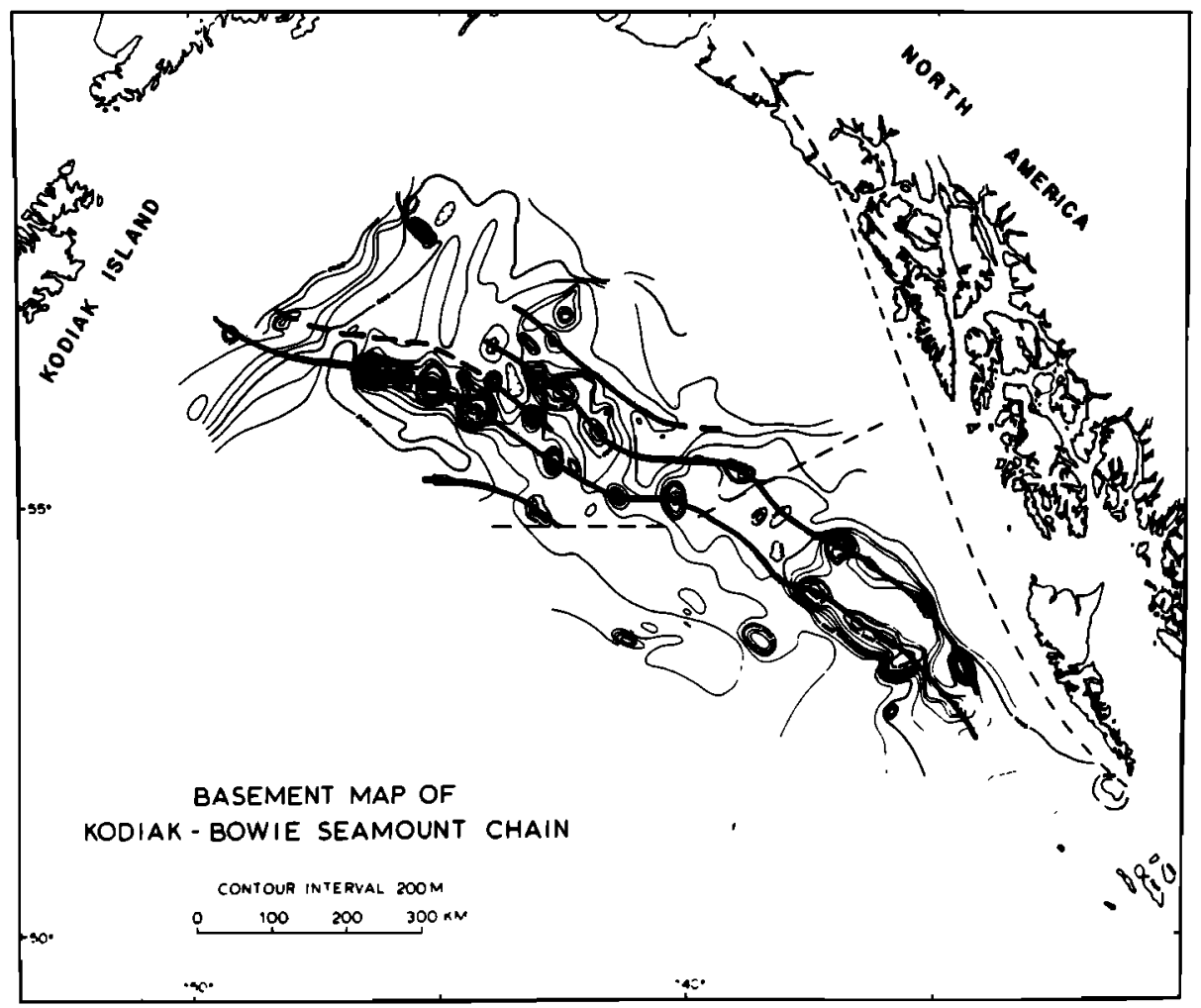

Fig. 7. Bathymetry and loci of individual shield volcanoes along the Pratt-Welker (or Kodiak-Bowie) chain. Straight lines mark the outer boundaries of outer shields. Bathymetry is from a basement map of Silver et al. [1974].
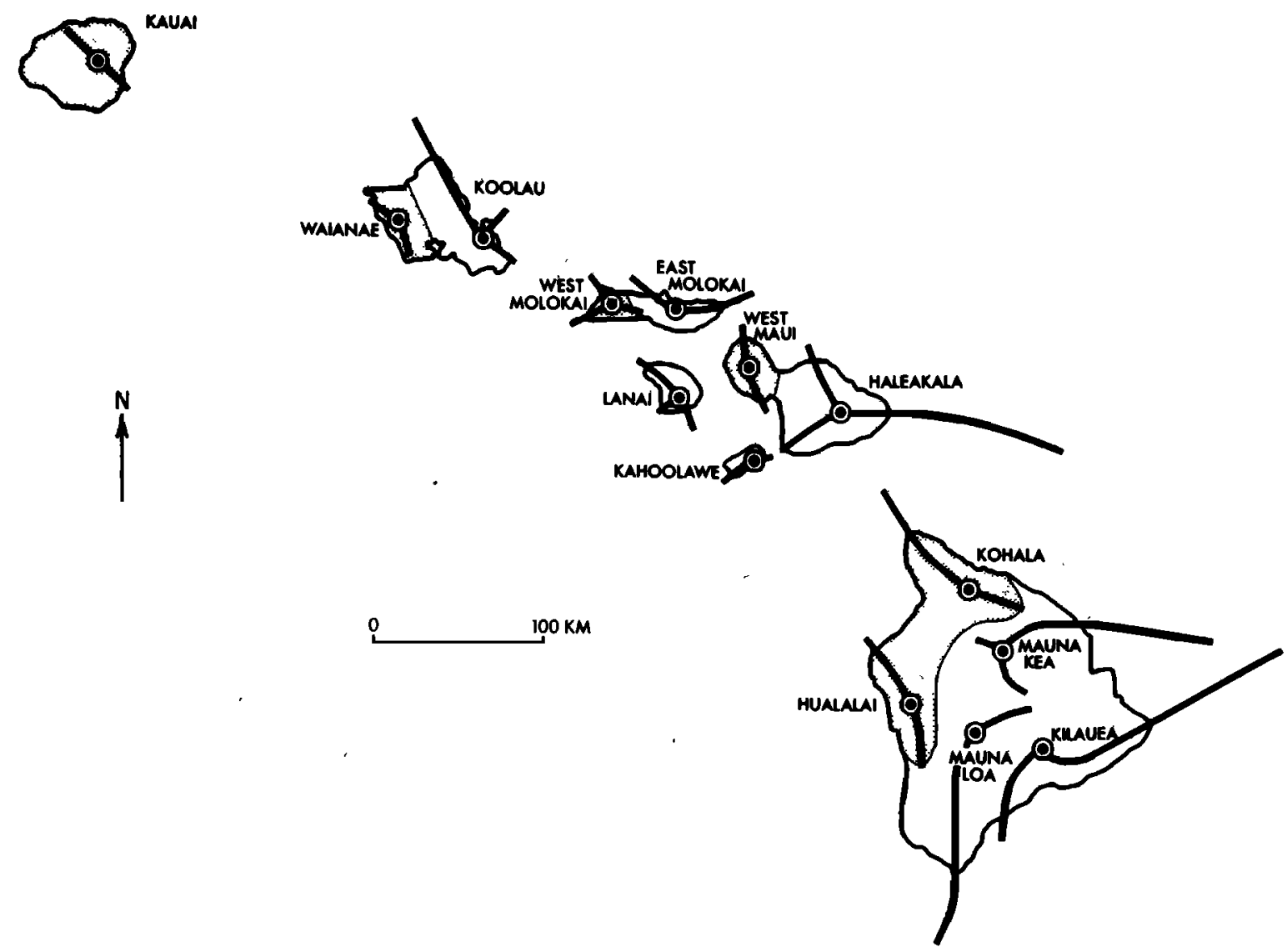

Fig. 8. Map showing the southeastern part of the Hawaiian Archipelago. The six volcanoes shown in the stippled pattern grew as 'isolated' edifices; the eight unstippled volcanoes grew later and were buttressed by the earlier-formed edifices [after Fiske and Jackson, 1972]. 


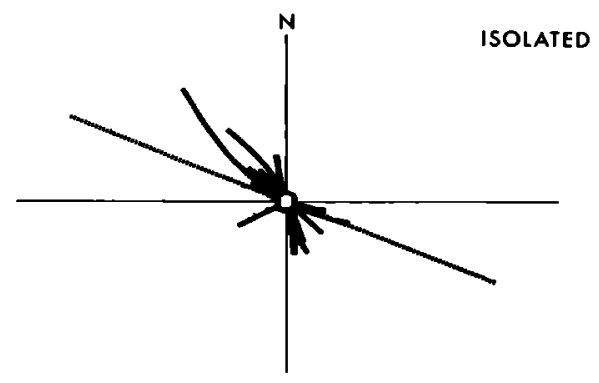

a

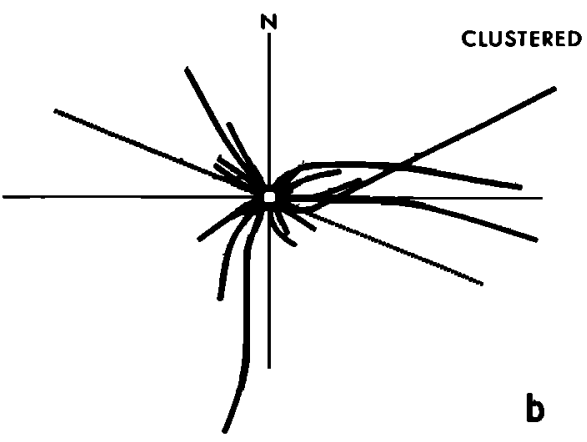

Fig. 9. Rose diagrams showing Hawaiian rift segments radiating from an imaginary center: $(a)$ rifts of isolated volcanoes, $(b)$ rifts of clustered volcanoes. The dashed line marks the overall trend of the Hawaiian chain [after Fiske and Jackson, 1972].

$\mathrm{N} 75^{\circ} \mathrm{E}$ ) [Endo, 1971]. Studies of first motion of 5-km and deeper earthquakes on the south flank of Kilauea, away from the rift zone, show that the average azimuth of inferred maximum stress directions strikes about $\mathrm{N}^{\circ} 5^{\circ} \mathrm{W}$, 'within $20^{\circ}$ of normal to the trends of east-west fissures and the Koae faults' [Koyanagi and Endo, 1971, p. D94]. These results are entirely compatible with the maximum compressional direction predicted by Fiske and Jackson [1972]. More recent work by Ward and Gregersen [1973] on first-motion studies of shallow Kilauean earthquakes yields different nodal plane solutions and more diverse $P$ directions than those of Endo [1971], some of which suggest that inferred maximum compressional axes lie in different quadrants in different domains of the volcano.

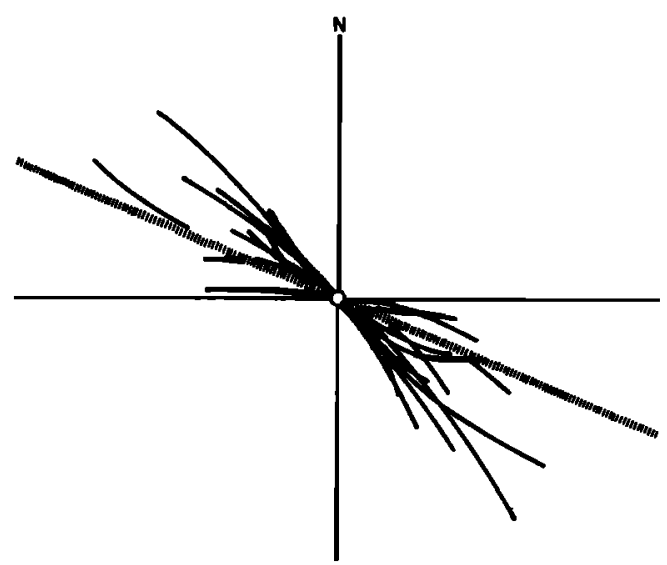

Fig. 10. Rose diagram showing loci of the Hawaiian chain radiating from an imaginary center. Loci are those of Figure 2 . The dashed line marks the overall trend of the Hawaiian chain.
First-motion studies on Kilauean earthquakes at depths of $20-45 \mathrm{~km}$, while preliminary, were also thought to be consistent with dominantly strike slip motion. Dominant directions of inferred least stress axes are $\mathrm{N} 20^{\circ} \mathrm{E}$ and $\mathrm{S} 20^{\circ} \mathrm{W}$, whereas maximum stress axes strike $S 70^{\circ} \mathrm{E}$ with dips of $0^{\circ}-60^{\circ}$ (E. T. Endo, personal communication, 1972). Again, more recent work by Ward and Gregersen [1973] on first-motion studies of five earthquakes in the depth range $15-27 \mathrm{~km}$ beneath Kilauea yield different nodal planes and different $P$ directions than those of Endo. Deeper earthquakes are believed to be caused by some mechanism of fluid injection at intermediate levels of the lithosphere [Raleigh, 1972; Koyanagi et al., 1972], but the depth at which they begin to be influenced by the edifice is moot.

At the present time the first-motion data from Hawaii itself, both at shallow and at deep levels, are internally inconsistent, and until the variability in nodal plane orientations and compressional and dilatational distributions are better understood, the data lend little support to any specific hypothesis of present-day maximum $\left(S_{1}\right)$ stress directions either within the edifices or in the dynamically disturbed domains beneath them.

Sykes and Sbar [1973] show solutions for four central Pacific plate earthquakes, all located well away from linear island chains. Each of these solutions is interpreted to be of the thrust type. The $\boldsymbol{P}$ directions of these earthquakes are not given, nor are the dips of the thrust solutions. Sykes and Sbar contend that intraplate earthquakes slowly change from normal to thrust solutions as distance away from a spreading ridge increases.

Stress orientations that cause strike slip rather than thrusttype dip slip motions differ only in the orientation of the intermediate $\left(S_{2}\right)$ principal stress, which is vertical in the former case and horizontal in the latter. If the ranges of minimum $\left(S_{3}\right)$ and intermediate $\left(\boldsymbol{S}_{2}\right)$ stresses actually have similar magnitudes within lithospheric plates, as seems likely, then the distributions of earthquake solutions showing either thrust or strike slip orientations will be quite sensitive to their positions relative to spreading rises, trenches, or linear island chains. This conclusion seems to be consistent with both the observations of Sykes and Sbar [1973] and those of this paper.

Although some of the inferred stress directions now calculated for the Pacific plate lie with $P$ in the northwest quadrant, the data are presently too few and rest on assumptions not yet completely resolved. We look forward to more precisely defined earthquake first-motion studies.

In continental areas it has been stated that there is good agreement between the inferred stresses derived from earthquake first-motion studies and in situ measurements of stresses in boreholes measured by overcoring and hydraulic fracture techniques [Raleigh et al., 1972; Sykes and Sbar, 1973]. In our opinion, however, there are significant uncertainties in interpretations of even highly precise earthquake data in the vicinities of volcanic terranes. Some examples are as follows.

1. All determinations of stress orientations from earthquake first-motion studies are based on some assumed geometry of displacements that give rise to the radiation field of compressional and dilatational waves. Most of the focal mechanism solutions for stress orientations discussed in recent papers are of the double-couple conjugate shear type, but other types of motion have been postulated [Hodgson and Stevens, 1964]. The relationship between the true maximum $\left(S_{1}\right)$ principal stress direction and the inferred compressional stress direction from first motions ( $P$ of Sykes and Sbar [1973]) 
depends on the actual mechanism of rock failure. This may involve simple slip on a fracture surface, slip on conjugate fracture planes of uncertain angular relationship, extension in a direction normal to fracture surfaces, creation of a new fracture in previously unfractured rock, or more complicated forms of motion. Where a fluid phase is present, the actual failure conditions also depend on the fluid pressure and the distribution of effective principal stresses ( $\sigma$ in the notation of Raleigh et al. [1972]) rather than on total principal stresses $(S)$. Thus we conclude that $S_{1}$ and $\sigma_{1}$ do not necessarily have any simple relationship to the compressional directions $P$ derived from earthquake first motions.

2. Depending on whether faulting occurs on a previously fractured surface or in intact rock, the angular uncertainty in deriving the maximum $(S)$ principal stress direction from double-couple solutions of earthquake data may be at least as great as $\pm 20^{\circ}$, depending on the type of fault failure, at low confining pressures. At confining pressures equivalent to mantle depths the expected angular uncertainty should be smaller, other factors remaining the same. This conclusion was established by extensive systematic studies in Rangely, Colorado, where a great body of data was generated on fault orientations, rock properties, laboratory determinations of failure mechanisms, and in situ measurements of stress [Raleigh et al., 1972, appendix]. However, the effective confining pressure may be severely reduced by high fluid pressures in magmatic source regions, so that fluid-filled preexisting fractures may be very much weaker than intact rock. In such cases we can only say that $S_{1}$ is likely to lie in the same quadrant as $P$ [Sykes and Sbar, 1973], that is, within a range of $\pm 45^{\circ}$.

3. Most first-motion studies currently reported within the Pacific plate are beneath or in the vicinity of volcanic edifices whose own internal stress fields are complex and influenced by near-neighbor buttressing effects [Fiske and Jackson, 1972].

\section{Factors Contributing to Resultant Stresses in the Pacific Plate}

Many different factors could, in principle, contribute to the states of stress in the lithosphere that control the orientations and senses of offset of volcanic loci and the rift directions of isolated volcanoes. Broadly speaking, there are two categories of stressed states, either of which might locally dominate the resultant stress orientations. The first category may be called inherent stresses and includes those stresses inherited from factors that controlled the strain history of the rock. These include volume changes due to changes of temperature, pressure, and changes of chemical and mineralogical states. The second category consists of stresses transmitted through the lithosphere by various forms of normal and shearing stresses acting at its boundaries [Nadai, 1963, p. $420 \mathrm{ff}$.]. Geologically, the inherent stresses are mainly the resultants of long-term changes, whereas the transmitted stresses are virtually instantaneous consequences of present-day lithospheric motion relative to plate boundaries and the underlying asthenosphere.

One source of transmitted stresses can arise from various types of interference with rigid body motion of the lithosphere caused by plate convergence or divergence [Seeger, 1973], irregularities of boundaries, and so on. Another source of transmitted stresses could be produced by the traction or degree of 'coupling' between lithosphere and asthenosphere due to any convective motion of material in the asthenosphere, particularly if this motion involves variable flow rates as proposed by Shaw [1973] and Shaw and Jackson [1973] or if the asthenosphere is subjected to variable degrees of partial melting [Lachenbruch, 1973a]. A third possible source of transmitted stresses is suggested by the spreading model of Lachenbruch [1973b]; if conduit pressure can vary with position along midoceanic ridges, then a source of stress can arise from horizontal variations in boundary forces related to local spreading rates. Similar effects related to force balances in mantle convection were discussed by Solomon and Sleep [1974]. We concur with their conclusion that quantitative modeling of intraplate stress is the 'next important calculation to perform.'

Turcotte and Oxburgh [1973] have proposed that thermal stresses and bending stresses due to the motion of lithospheric plates on a nonspherical earth may be responsible for crustal extension and the formation of volcanic island chains. Although bending stresses are normally considered to be resultants of transmitted stresses, both of the proposed mechanisms are consequences of the long-term history of plate motion. Both mechanisms undoubtedly influence the local states of stress in the lithosphere, but it seems unlikely to us that these stresses can be completely responsible for the patterns of volcanic loci. Also, since the lithosphere behaves as a viscoelastic body [Walcott, 1970a], it is not entirely clear to what extent such stresses may have relaxed during the time required for their generation, and at least some chains appear to have begun as long as 70-100 m.y. ago [Scholl et al., 1971; Clague and Jarrard, 1973b]. Additional drawbacks to these mechanisms are that the vectors of tensional stress proposed by Turcotte and Oxburgh [1973] do not predict the curvature, the sense of rotation, or the time sequence of en echelon overlaps of loci discussed by Jackson et al. [1972] and by Shaw [1973].

In the immediate vicinity of volcanic island chains the lithosphere is also subjected to at least two forms of inherent and transmitted stresses related to the effects of magmatic intrusion of the lithosphere and loading of its surface by volcanic edifices. Walcott [1970b] has proposed that the flexural response of the lithosphere to volcanic loading causes the development of an axial discontinuity that maintains the linearity of the volcanic chain by inducing compressive stresses at the base of the lithosphere along the flanks of the ridge. Although this effect, too, is undoubtedly real, its appeal as a guiding mechanism is reduced by the fact that the axial discontinuity is a consequence of viscoelastic relaxation that follows after volcanic loading. If injection of the lithosphere were controlled by the local flexural response to loading, then flexure in the longitudinal direction ahead of the volcanic chain should influence the orientations of the initial parts of succeeding volcanic loci. These orientations presumably could be at virtually any angle to the trend of the chain, including the normal. Furthermore, the distance between Kauai (near the origin of one of the two volcanic loci of the southeastern Hawaiian Islands) and the preexisting ridge front is greater than the flexural wavelength given by Walcott [1970b]; the position of Niihau adjacent to Kauai is not relevant because it formed much later [Jackson et al., 1972, Figure 3]. We concur with Walcott [1970b] that the flexural model would be an effective guide to orientations of volcanic island chains if magma were equally available everywhere. In Hawaii, however, the source region of tholeiitic melting appears to propagate in advance of the front of volcanic loading [Shaw, 1973; Shaw and Jackson, 1973]. Although Shaw [1973] pointed out the importance of Walcott's flexural model and the agreement between rates of propagation of volcanic loading and subsidence, we now conclude that it does not provide an internally consistent 
explanation for the configurations, senses of overlap, or relative chronologies of lines of volcanic loci.

\section{Previous Models Invoking Fixed Stress Orientations With Time}

Some authors [Betz and Hess, 1942; Jackson and Wright, 1970; Turcotte and Oxburgh, 1973] have proposed that the Pacific lithosphere contains a system of stresses that has maintained a fixed orientation in time and that the volcanic progression represents some form of propagating fracture that taps sources of magma available in the mantle. The model proposed in the present paper is conceptually similar except that we conclude that the resultant stress distributions lie at different attitudes than heretofore proposed, that they vary with time, and that they are controlled by the net dynamic effects imparted by the global kinematics of plate motion.

The possibility has occurred to us that the angular relationship between the Emperor and Hawaiian chains and the en echelon senses of overlap of other volcanic loci in the Pacific plate are geometrically consistent with a conjugate model of finite strain produced by a nonrotational force field that induced uniform compressional stresses in the northwest quadrant and tensional stresses in the northeast quadrant of the plate. This geometry has been demonstrated for contemporaneously formed fractures on a smaller scale by Duffield and Nakamura [1973]. For such a model to be internally consistent the same force field must have been operative over the entire duration of volcanism (i.e., for nearly 70 m.y.). Age sequences and curvatures of volcanic loci, according to this model, might conceivably be interpreted according to the time progression of primary and higher-order shear couples within the hierarchy discussed by Moody and Hill [1956].

Our general objections to a conjugate strain model for propagating volcanic chains of the Hawaiian-Emperor type, where age progressions are definitely established and where the position of the magma source appears to have remained roughly fixed relative to the deep mantle, include the following.

1. There is no evidence that any significant intraplate finite strain has been imposed on the Pacific lithosphere in the localities of linear chains.

2. We find it difficult to reconcile models based on concepts of intraplate conjugate shear systems, whether they are located in the lithosphere or beneath it, with current kinematic models of plate translation and with the dynamic models of asthenospheric melting and counterflow proposed by Shaw [1973] and Shaw and Jackson [1973].

3. Even if the kinematic problems of fracture propagation relative to the lithosphere and deep mantle were reconciled with a model of conjugate shear, there would be no requirement for progressive volcanism, for synchronization of volcanic episodes, or for similar bend ages for different chains of similar propagating types.

Vogt [1974] combined the shear hypothesis with that of a relatively fixed melting anomaly and suggested that the locations of Hawaiian shields were produced during the passing of that anomaly under a preexisting conjugate fracture system. This model is not subject to argument (3) above but fails to explain the curvature of the loci and the time-distance-volume relations between the shields [Jackson et al., 1972; Shaw, 1973; Shaw and Jackson, 1973; Bargar and Jackson, 1974]. Furthermore, one would expect the volcanoes on Vogt's northeasttrending 'fractures' on the Hawaiian and Emperor chains to be of similar ages. One of these fractures includes Niihau and
Kauai, which are known to be widely different in age [Jackson et al., 1972]; another includes several shields in the vicinity of Midway, where similar age reversals across different loci are known to exist [Dalrymple et al., 1974; Clague et al., 1975].

The stress model of Turcotte and Oxburgh [1973], while not strictly involving fixed stress orientations with time, resembles the fixed stress models except that in detail, stress orientations depend on the directions and rates of plate translation with time. Given a northward translation of the Pacific plate and the en echelon loci of Jackson et al. [1972], they predict on the basis of the Coulomb-Navier theory of fracture that the tensional direction $\left(S_{3}\right)$ has remained at $N 13^{\circ} \mathrm{W}$ during the entire duration of Hawaiian volcanism. In addition to assuming a specific failure criterion, they also ignore effects of transmitted boundary forces at plate margins and across the lithosphereasthenosphere zone of coupling. While the stresses that they discuss are real, there is little reason to suppose that they have dominated the resultant stress field in the plate over the last 42 $\mathrm{m}, \mathrm{y}$.

\section{Force Balances That Have Resulted in Rotations of Stresses in the Pacific Lithosphere}

The equilibrium condition for forces acting in the plane of a plate requires that there be no net torque relative to geocentric coordinates [Solomon and Sleep, 1974]. However, the fact that tectonic conditions around the Pacific plate margins have varied in time, as evidenced by plate movement and consumption, indicates that there have been locally varying magnitudes of horizontal force vectors acting from place to place at plate margins with time. Furthermore, it is likely that there have been variations in magnitudes and locations of tractive coupling between the plate and its underlying asthenosphere through time. The orientations and magnitudes of resultant stress states within the plate must have reflected the local resolutions of all such forces and hence must also have varied in time even though the sum of all boundary forces at any given time must have been zero if the criterion of mechanical equilibrium (i.e., no overall acceleration of plate motion) was maintained. Basically, this means that any change of boundary forces in one location must have been balanced by equal and opposite changes elsewhere, but this does not preclude the possibility, for example, that a direction of relative compressive stress may not have become one of relative tension with respect to previous stress states in the plate. The net dynamic effect of such balanced variation in bounding forces therefore requires a rotation of resultant principal stress direction in the Pacific plate with time.

The likely combined effect of the various forces acting at plate boundaries would be to impart a tendency for rotations of resultant stress directions in the plate as a whole, although there could be a complex system of stress states within and below the plate at any special sites dominated by inherent stresses or by local dynamic effects (such as are presently evident in the variations of stress orientations within the volcanic edifices of Hawaii). Since it is very improbable that the vector sum of the dominant horizontal components of the boundary forces will always vary in the same sense over all plate margins, the net rotations of resultant stresses will act either in a clockwise or counterclockwise sense. Thus the sense and magnitude of the rotational effects will be governed by the time durations and variations of the force balances.

Although some of the inherent and transmitted stresses enumerated in the preceding sections lend themselves to quantitative evaluation, it is apparent that our knowledge of the 
complex interplay of forces affecting the resultant principal stresses is not yet sufficient to be treated quantitatively relative to present stress states, much less relative to variations over the last 70 m.y. However, it is our contention that there is a geologically simple pattern of resultant stress variations that are reflected in the curved en echelon orientations of volcanic loci that have delineated the resultant stress directions as magmatic fluids have risen through the lithosphere during growth of the Hawaiian chain of volcanoes. It seems most likely to us that the chronology and sense of overlap of loci of the Hawaiian and all other northwest-trending chains are principally controlled by conditions of resultant transmitted stresses dominated by a tendency for systematic but oscillatory right lateral rotations of horizontally transmitted stress directions. This conclusion does not explain those portions of the older, north-trending loci that now nearly parallel the midoceanic ridge axis, unless there was a change in the directions of principal transmitted stresses in the Pacific lithosphere prior to 40-50 m.y. ago and unless intraplate stresses were, at that time, subjected to dominantly left lateral rotations. Such a change may have resulted in part, as Handschumaker [1973] proposed, by a different orientation system between chain and spreading ridge than prevails at present, or it may have been a result of a different combination of other factors discussed above.

It appears to us, for the above reasons, that existing data favor the hypothesis of magma injection from a source in the asthenosphere into a rigid Pacific plate subjected to rotations of principal stress directions with time. The principal evidence that will permit a distinction between this hypothesis and others ultimately must be obtained from detailed geochronological mapping of volcanic edifices across the Pacific. Although the rotational model is favored as an explanation for loci of the Hawaiian-Emperor type, it is possible that there were situations where the rotational effect was small enough or null and the source of asthenosphere magma was sufficiently distributed that a nonrotational stress model was operative. The Line Islands may be an example of this possibility, since we have found it difficult to identify en echelon loci in this chain, and its edifices appear to be coeval [Schlanger et al., 1974].

\section{Changes in Plate Stresses With Time and Location in the Pacific}

Given our rotational hypothesis and the concept that magmatic fluids are injected in planes perpendicular to the minimum $\left(S_{3}\right)$ stress direction, it would appear from orientations of isolated rifts and loci orientations that the Pacific lithosphere is presently dominantly stressed with an in situ maximum $\left(S_{1}\right)$ stress oriented northwest-southeast and a minimum $\left(S_{3}\right)$ stress oriented northeast-southwest. Orientations of loci (Figures 2, 4, 6, and 7) suggest that this condition has obtained at least since the time of the Hawaiian-Emperor bend and the inception of the Tuamotu chain (over the last 40-50 m.y.) and that the dominant stress field at any given time during this span has been rather uniformly oriented over nearly the entire plate, from the Pratt-Welker to the Austral chains. Prior to that time the plate appears to have been dominantly stressed in another orientation, with the in situ maximum $\left(S_{1}\right)$ direction just west of north and the minimum $\left(S_{3}\right)$ direction just north of east, at least from the northern Emperors to the Ellice Islands (Figures 3 and 5). Hole 318 of the Deep-Sea Drilling Project [Schlanger et al., 1974] was drilled near the northern end of the Tuamotu chain, where off- set directions appear to be to the right (clockwise). Volcanogenic debris from these islands was dated at $50 \mathrm{~m}$.y. by paleontologic methods. At this time we cannot say whether the change from left- to right-stepping symmetry took place over a period of some 8-10 m.y. or is an artifact of uncertainties in correlation between radiometric and paleontologic time scales.

Such a change in the dominant sense of stress rotations in the Pacific plate, however, does not necessarily confirm Morgan's [1972a, b] contention that a change in direction of motion of the Pacific plate took place 40-55 m.y. ago. Indeed, Herron [1972] gives evidence that this plate has not changed its motion direction for the last $80 \mathrm{~m} . \mathrm{y}$., a time that predates the oldest known Emperor volcanism. However, some change in the boundary conditions of plate motions must have occurred in the period 40-50 m.y. ago, according to our model.

The assumption that lines of volcanic loci accurately track the direction of the resultant maximum $\left(S_{1}\right)$ principal stress in the upper part of the lithosphere (because injection is confined to planes normal to the minimum $\left(S_{3}\right)$ principal stress, which is nearly horizontal in the vicinities of volcanic fracture systems) has far-reaching implications as a tool for chronological correlation when it is combined with the assumption that the minimum $\left(S_{3}\right)$ stress direction in the Pacific plate is dominated in much of the plate by instantaneous transmitted stresses governed by the balance of forces at plate boundaries. Although we cannot completely discount local complications, the consistency of the pattern of loci within the Hawaiian ridge and the similarity of patterns in other linear island chains lead us to list the following possible consequences of these assumptions.

1. Within any segment of a volcanic chain containing several lines of volcanic loci formed during the same time interval, points on different lines that define a set of parallel tangents should be of the same age [Jackson et al., 1972]. Shaw [1973, pp. 1512-1513] came to a similar conclusion on the basis of entirely different data involving time-distance-volume relations.

2. Families of curved loci within the Hawaiian chain define three or more episodic swings in the trace of the maximum $\left(S_{1}\right)$ principal stress during the last 40-50 m.y. with azimuths ranging from about $\mathrm{N} 30^{\circ} \mathrm{W}$ to $\mathrm{N} 80^{\circ} \mathrm{W}$. Similarly, maximum principal stress trajectories in the Emperor chain inferred by our method had episodic swings of azimuth ranging from northsouth to about $\mathrm{N} 45^{\circ} \mathrm{W}$, again with the possibility of about three episodes. Therefore the durations of these episodes can be estimated from their number and from the life-spans of the Hawaiian and emperor chains; the average duration of an episode is about $12 \mathrm{~m} . \mathrm{y}$. if the total number of episodes is about six and the total time span is roughly 70 m.y.

3. Azimuths of lines of volcanic loci in different linear island chains that formed during the same general time intervals should have similar age progressions. This is borne out by existing knowledge of ages and the loci patterns shown in Figures 2, 3, 4, 5, 6, and 7. The inverse of this point is that if the general time interval is known for different island chains, then the chronological sequence should be given by the changes in the directions of tangents to lines of volcanic loci. Thus with continued refinement of age data and bathymetry it may be possible to derive a Pacific-wide volcanic chronology that is independent of interpretations of magnetic profiles or assumptions concerning rates of ocean floor spreading.

The fact that similar episodic variations are found in both normals to minimum $\left(S_{3}\right)$ principal stress directions as defined by lines of volcanic loci and in time-distance-volume 
relationships [Shaw, 1973] suggests that a casual connection is possible. The simplest explanation for swings in the stress direction is that there exist episodic variations in the magnitudes of equal and opposite force vectors at the plate boundaries. Such variations could occur with or without episodic changes in the direction or rates of Pacific plate translation. Episodic variations in time-distance-volume relationships, however, imply some form of compatible variations in material transport velocities in the asthenosphere.

A question left unresolved by Shaw and Jackson [1973] concerned the factors that control the locations of conspicuous melting anomalies of Hawaiian type in the central Pacific. It now seems likely, as they suggested was possible, that these locations are controlled by special combinations of lithospheric stresses that favor a greater than average rate of melt injection by hydraulic fracture from the asthenosphere into the lithosphere relative to other locations in the asthenosphere [Shaw and Swanson, 1970]. This in turn favors more rapid local transport rates in the asthenosphere to feed the nutrients of Hawaiian-type tholeiitic melting and also favors a greater chance to initiate a site of residual downwelling to hold the anomaly more or less anchored relative to the deep mantle. The general process, however, is considered to be potentially active everywhere in the asthenosphere and should be clarified in the chronologic histories of more widespread volcanic features on the ocean floors. It is analogous to the process proposed by Shaw et al. [1971] to explain the episodicity of continental magmatism.

The principal remaining question concerns the orientation of $S_{3}$ in the lithosphere versus the lithospheric translation direction relative to a melting anomaly in the asthenosphere. Three simple possibilities appear to exist: (1) $S_{\mathrm{a}}$ is always normal to the translation direction, and the direction itself varies with time in a manner indicated by curvatures of individual lines of volcanic loci (Figures 2, 3, 4, 5, 6, and 7); (2) the translation direction is constant with time, and $S_{3}$ varies with the time because the postulated rotational effect varies with time in the lithosphere; or (3) some combination of these factors has obtained.

The second of the above possibilities appears to be the simplest assumption consistent with propagation directions and terminations of lines of volcanic loci. If the translation direction of the plate varied continuously with time relative to a melting anomaly fixed in the asthenosphere, it would appear likely that a given linear locus of volcanic shields would have tended to track continuously the motion direction without termination. The second hypothesis implies that initial injection of the lithosphere along a given locus could have had any angular relationship to the translation direction depending on the stress orientation at that time. At times when the resultant stress rotation was small or null the locus of volcanism tracked the translation direction if the $S_{\mathrm{s}}$ direction was perpendicular to that direction. When the rotational effect was large, the direction of loci deviated from the translation direction, but such loci could not propagate very far from the mean trend of the composite chain because the melting anomaly in the asthenosphere was held more or less fixed relative to the deep mantle by the anchoring effect of the downwelling residua from melting [Shaw and Jackson, 1973].

The above hypothesis suggests that when the rotational effect was large, a given segment of the composite volcanic ridge developed several more or less synchronous short loci at high angles to the average trend of a chain. A small or null rotation, on the other hand, would have resulted in fewer and longer lines of volcanic loci more nearly parallel to the average trend. These implications appear to be consistent with the patterns observed for the Hawaiian ridge and Emperor seamount chain. For example, the pattern near Midway on the Hawaiian ridge could be explained as a relatively major rotational episode; this area was considered paradoxical to the idea of simple linear progression of the Hawaiian chain by Shaw [1973]. The loci pattern of much of the Emperor chain, conversely, would be interpreted as having been formed during a period of relatively small average rotational excursions from a constant stress orientation.

Either the rotational effect or a variation of translation direction could have produced the senses of overlap observed for volcanic loci, although a rather specialized and intermittent variation of motion directions would have been required to produce a consistent sense of overlap by the latter mechanism. The rotational effect, on the other hand, automatically produced a sense of right lateral en echelon overlap when the stress rotation was clockwise (Hawaiian ridge), and vice versa (Emperor chain), because of the relative confinement of the injection zone above the melting anomaly and the continuous translation of lithosphere in the direction of the average trend.

The interpretations of this paper reveal an important constraint on the relationships between translation directions and stress states relative to the transition from Cretaceous to Cenozoic spreading directions at the position of the Hawaiian melting anomaly. According to our model, the Emperor chain developed with a progression similar to that of the Hawaiian chain except that the lithospheric plate injected by magma at that time was being subjected to variable but generally weak counterclockwise resultant stress rotations. This is consistent with the smaller number and greater length of volcanic loci in the Emperor chain (Figure 3) and implies that the $S_{3}$ direction in the plate in which the Emperor seamounts formed was more nearly normal to the trend of the chain during much of Emperor time.

The sense of offset in the Emperor seamounts is similar to that in the Marshall-Gilbert-Ellice islands, and the loci of volcanism also lie at low angles to the propagation direction in both chains. These data imply that prior to 40-50 m.y. ago, both chains lay in the same plate and that the sense of resultant stress rotations in that plate was counterclockwise. If the generalized trend of these chains also maps the propagation direction of that plate during the period prior to $40-50 \mathrm{~m} . \mathrm{y}$. ago, then the direction was slightly west of north, a direction not easily reconciled with Herron's [1972] reconstruction of Pacific plate motions during this period. However, if the Emperor fracture zone represents an active transform fault during the period of formation of the Emperor chain [Rea, 1970; Larson and Chase, 1972], then the low angles of loci to the general trend of the chains and the relatively long lengths of loci in both the Emperor and the Marshall-Gilbert-Ellice chains are consistent with both a relatively fixed melting anomaly and a northward translation of that plate during the period of time in question. Our interpretation is that whether this plate was the ancestral Pacific plate or one north of it, during Emperor and Marshall-Gilbert-Ellice time the trace of $S_{1}$ in the lithosphere lay just west of the present north direction and the trace of $S_{9}$ was normal to that direction. We feel that the common sense of resultant stress rotations and angular relations between loci and propagation directions imply that the Emperor and Marshall-Gilbert-Ellice chains were consequences of the dynamic regime in a single plate. We have no 
direct evidence as to the sense of rotation or direction of motion of other adjacent plates during the period between $40-50$ and 70-100 m.y. B.P.

There appears to have been a Pacific-wide synchronization of rotational stress episodes. If continued age dating of volcanic edifices in linear island chains proves this to be the case, then an independent chronology for intraplate volcanic episodes could be constructed independent of, but analogous to, the chronology furnished by magnetic reversals. Furthermore, there is a possible correlation of these stress episodes with magmatic time and volume episodes in the HawaiianEmperor chain. These relations suggest the possibility of Pacific-wide synchronization of magmatic episodes both in the center of the plate and at its margins. According to thermomechanical models of magma generation [Shaw, 1973; Shaw and Jackson, 1973], synchronous variations in both the stress states in the lithosphere and the rates of melting in the asthenosphere could be related to variable tractions between the two [Lachenbruch, 1973a] and could involve either variable velocities of horizontal flow in the asthenosphere or variable velocities of both asthenospheric flow and plate translation.

Acknowledgments. We thank our colleagues E. R. Oxburgh, then at Stanford University, and E. Endo and R. W. Kistler, of the U.S. Geological Survey, for critically reviewing the manuscript during preparation. Additional constructive criticism was provided by $\mathbf{N}$. H. Sleep, of Northwestern University.

\section{REFERENCES}

Bargar, K. E., and E. D. Jackson, Volumes of individual shield volcanoes along the Hawaiian-Emperor chain, U.S. Geol. Surv. J. Res., 2, 545-550, 1974.

Betz, F., Jr., and H. H. Hess, The floor of the North Pacific Ocean, Geogr. Rev., 32, 99-116, 1942.

Chase, T. E., H. W. Menard, and J. Mammerickx, Bathymetry of the North Pacific, charts 1-10, Scripps Inst. of Oceanogr., La Jolla, Calıf., 1973.

Chubb, L. J., The structure of the Pacific basin, Geol. Mag., 7I, 289-302, 1934.

Clague, D. A., and G. B. Dalrymple, Age of Koko seamount, Emperor seamount chain, Earth Planet. Sci. Lett., 17, 411-415, 1973.

Clague, D. A., and R. D. Jarrard, Hot spots and Pacific plate motion (abstract), Eos Trans. $A G U, 54(4), 238,1973 a$

Clague, D. A., and R. D. Jarrard, Tertiary Pacific plate motion deduced from the Hawaiian-Emperor chain, Geol. Soc. Amer. Bull., 84, 1135-1154, $1973 b$.

Clague, D. A., G. B. Dalrymple, and R. Moberly, Petrography and $\mathrm{K} / \mathrm{Ar}$ ages of dredged volcanic rocks from the western Hawaiian ridge and the southern Emperor seamount chain, Geol. Soc. Amer. Bull., 86, in press, 1975 .

Dalrymple, G. B., M. A. Lanphere, and E. D. Jackson, Contributions to the petrography and geochronology of volcanic rocks from the leeward Hawaiian Islands, Geol. Soc. Amer. Bull., 85, 727-738, 1974.

Dalrymple, G. B., R. D. Jarrard, and D. A. Clague, Potassium-argon ages of some volcanic rocks from the Cook and Austral islands, Geol. Soc, Amer. Bull., 86, in press, 1975

Dana, J. D., United States Exploring Expedition, During the Years $1838,1839,1840,1841,1842$, vol. 10, Geology, Sherman, Philadelphia, Pa., 1849.

Dana, J. D., Manual of Geology, 2nd ed., p. 828, lvison, Blakeman, Taylor, New York, 1876.

Dana, J. D., Revised Textbook of Geology, 5th ed., p. 482, American, New York, 1897

Duffield, W. A., and K. Nakamura, A photogeologic method for determining the direction of horizontal dilation from patterns of en echelon fracturing, U.S. Geol. Surv. J. Res., 1, 283-287, 1974.

Endo, E. T., Focal mechanisms for the May 15-18, 1970 shallow Kilauea earthquake swarm, M.S. thesis, San Jose State Coll., San Jose, Calif., 1971.

Fiske, R. S., and E. D. Jackson, Orientation and growth of Hawaiian rifts: The effect of regional structure and gravitational stresses, Proc. Roy. Soc. London, 329, 299-326, 1972.

Handschumaker, D., Formation of the Emperor seamount chain, Nature, 244, 150-153, 1973.

Herron, E. M., Sea-floor spreading and the Cenozoic history of the east-central Pacific, Geol. Soc. Amer. Bull., 83, 1671-1692, 1972.

Hodgson, J. H., and A. E. Stevens, Seismicity and earthquake mechanisms, in Research in Geophysics, vol. 2, Solid Earth and Interface Phenomena, edited by $\mathrm{H}$. Odishaw, pp. 27-59, MIT Press, Cambridge, Mass., 1964.

Jackson, E. D., and T. L. Wright, Xenoliths in the Honolulu volcanic series, Hawaii, J. Petrology, II, 405-430, 1970.

Jackson, E. D., E. A. Silver, and G. B. Dalrymple, Hawaijan-Emperor chain and its relation to Cenozoic circumpacific tectonics, Geol. Soc. Amer. Bull., 83, 601-617, 1972.

Koyanagi, R. Y., and E. T. Endo, Hawaiian seismic events during 1969, U.S. Geol. Surv. Prof. Pap. 750-C. C158-C164, 1971.

Koyanagi, R. Y., H. L. K rivoy, and A. T. Okamura, The 1962 Kaoiki, Hawaii, earthquake and its aftershocks, Bull. Seismol. Soc. Amer., 56, $1317-1335,1966$.

Koyanagi, R. Y., D. A. Swanson, and E. T. Endo, Distribution of earthquakes related to mobility of the south flank of Kilauea volcano, Hawaii, U.S. Geol. Surv. Prof. Pap. 800-D, D89-D97, 1972.

Krummenacher, D., and J. Noetzlin, Ages isotopiques K/A de roches prélevees dans les possessions françaises de Pacifique, Bull. Soc. Geol. Fr., 8, 173-175, 1966.

Lachenbruch, A. H., Differentiation and the gravitational driving force for material rising at an oceanic ridge, J. Geophys. Res., 78, 825-831, 1973a.

Lachenbruch, A. H., A simple mechanical model for oceanic spreading centers, J. Geophys. Res., 78, 3395-3417, $1973 b$.

Larson, R. L., and C. G. Chase, Late Mesozoic evolution of the western Pacific Ocean, Geol. Soc. Amer. Bull., 83, 3627-3644, 1972.

Macdonald, G. A., and A. T. Abbott, Volcanoes in the Sea: The Geology of Hawaii, p. 441, Hawaii University Press, Honolulu, 1970.

Mammerickx, J., S. M. Smith, I. L. Taylor, and T. E. Chase, Bathymetry of the South Pacific, I.M.R. Tech. Rep. 46A, chart 13, Scripps Inst. of Oceanogr., La Jolla, Calif., 1973.

Molnar, P., and T. Atwater, Magnetic anomalies and evolution of the South Pacific: Implications for fixed hot-spots (abstract), Eos Trans. $A G U, 54(4), 240,1973$.

Moody, J. D., and M. J. Hill, Wrench-fault tectonics, Geol. Soc. Amer. Bull., 67, 1207-1246, 1956.

Morgan, W. J., Deep mantle convection plumes and plate motions, Amer. Ass. Petrol. Geol. Bull., 56, 203-312, 1972a.

Morgan, W. J., Plate motions and deep mantle convection, Geol. Soc. Amer. Mem., 132, 7-22, $1972 b$.

Nadai, A., Theory of Flow and Fracture of Solids, p. 705, McGrawHill, New York, 1963.

Powers, S., Tectonic lines in the Hawaiian Islands, Geol. Soc. Amer. Bull., 28, 501-514, 1917.

Raleigh, C. B., Earthquakes and fluid injection, Amer. Ass. Petrol. Geol. Mem. I8, 273-279, 1972.

Raleigh, C. B., J. H. Healy, and J. D. Bredehoeft, Faulting and crustal stress at Rangely, Colorado, in Flow and Fracture of Rocks, Geophys. Monogr. Ser., vol. 16, edited by H. C. Heard, I. Y. Borg, N. L. Carter, and C. B. Raleigh, pp. 275-284, AGU, Washington, D. C., 1972

Rea, D. K., Changes in structure and trend of fracture zones north of the Hawaiian ridge and relation to sea floor spreading, J. Geophys. Res., 75, 1421-1430, 1970.

Richter, D. H., J. P. Eaton, K. J. Murata, W. V. Ault, and H. L. Krivoy, Chronological narrative of the 1959-1960 eruption of Kilauea volcano, Hawaii, U.S. Geol. Surv. Prof. Pap. 537-E. 73, 1970.

Schlanger, S. O., E. D. Jackson, R. E. Boyce, H. E. Cook, H. Jenkyns, D. A. Johnson, A. G. Kaneps, K. R. Kelts, E. Martini, C. L. McNulty, and E. L. Winterer, Leg 33, Deep-Sea Drilling Project: Testing a hot spot theory, Geotimes, 19. 16-20, 1974.

Scholl, D. W., J. S. Creager, R. E. Boyce, R. J. Echols, T. J. Fullam, J A. Grow, I. Koizumi, H. Lee, H. Y. Ling, P. R. Supko, R. J. Stewart, and T. R. Worsley, Deep-Sea Drilling Project leg 19, Geotimes, I6(11), 12-15, 1971 .

Seeger, C. R., Plate tectonics, mantle plumes, and the origin of Hawaiian Islands (abstract), Eos Trans. AGU, 54(4), 240, 1973.

Shaw, H. R., Mantle convection and volcanic periodicity in the 
Pacific; Evidence from Hawaii, Geol. Soc. Amer. Bull., 84 1505-1526, 1973.

Shaw, H. R., and E. D. Jackson, Linear island chains in the Pacific: Result of thermal plumes or gravitational anchors?, J. Geophys. Res., 78, 8634-8652, 1973.

Shaw, H. R., and D. A. Swanson, Eruption and flow rates of flood basalts, in Proceedings of the Second Columbia River Basalt Symposium, edited by E. H. Gilmour and D. Stradling, pp. 271-299, Eastern Washington State College Press, Cheney, 1970.

Shaw, H. R., R. W. Kistler, and J. F. Evernden, Sierra Nevada plutonic cycle, 2, Tidal energy and a hypothesis for orogenicepeirogenic periodicities, Geol. Soc. Amer. Bull., 82, 869-896, 1971.

Silver, E. A., R. Von Huene, and J. Crouch, Tectonic significance of the Kodiak-Bowie seamount chain, northeastern Pacific, Geology. 2. 147-150, 1974.

Solomon, S. C., and N. H. Sleep, Some simple physical models for absolute plate motions, J. Geophys. Res., 79. 2557-2567, 1974.

Stearns, H. T., Geology of the State of Hawaii, p. 226, Pacific, Palo Alto, Calif., 1966.

Sykes, L. R., and M. L. Sbar, Interplate earthquakes, stresses in the lithosphere, and the driving mechanism of plate tectonics, Nature $245,298-302,1973$.

Turcotte, D. L., and E. R. Oxburgh, Mid-plate tectonics, Nature, 244. 337-339, 1973.

Turner, D. L., R. B. Forbes, and C. W. Naeser, Radiometric ages of
Kodiak seamount and Giacomini guyot in the Gulf of Alaska: Implications for circumpacific tectonics, Science, 182, 579-581, 1973.

Turner, D. L., R. B. Forbes, and C. W. Naeser, Geochronology and genesis of the Kodiak-Bowie chain in the Gulf of Alaska (abstract), Eos Trans. AGU, 56(12), 1186, 1974.

Unger, J. D., and P. L. Ward, Travel time delays and tectonic stress from a subcrustal Hawaiian earthquake (abstract), Eos Trans. $A G U, 56(12), 1150,1974$.

Vogt, P. R., Volcano spacing, fractures and thickness of the lithosphere, J. Geophys. Res., 75, 3941-3954, 1970a.

Walcott, R. I., Flexural rigidity, thickness and viscosity in the lithosphere, J. Geophys. Res., 75, 3941-3954, 1970a.

Walcott, R. I., Flexure of the lithosphere in Hawaii, Tectonophysics, 9, 435-446, $1970 b$.

Ward, P. L., and S. Gregersen, Comparison of earthquake locations determined with data from a network of stations and small triparitite arrays on Kilauea volcano, Hawaii, Bull. Seismol. Soc. Amer., 63, 679-711, 1973.

Williams, H., Geology of Tahiti, Moorea and Maiao, Bishop Mus. Bull., 105, 86, 1933.

(Received July 23, 1974;

revised January 9,1975

accepted January 27,1975 .) 